\title{
SORPTION STUDIES ON THE REMOVAL OF NAPHTOL-AS DYE USING IRON FILINGS AS ADSORBENT
}

\author{
C. M. Ngwu* ${ }^{1}$, O. K. Amadi ${ }^{1}$, M. O. Mac-Kalunta ${ }^{1}$, and J. Onyeuwaoma ${ }^{1}$. \\ ${ }^{1}$ Department of Chemistry, Michael Okpara University of Agriculture Umudike, P.M.B 7267 \\ Umuahia, Abia State, Nigeria \\ *Correspondence author: kom4tngwu@ gmail.com, +234(0)8032145757 \\ Received 30 July 2020; accepted 13 November 2020, published online 30 March 2021
}

\begin{abstract}
This study investigated the potential of iron filings as low cost and environmentally friendly adsorbent for removing Naphthol AS dye from aqueous solutions. The batch-adsorption experiments were performed as a function of $\mathrm{pH}$, temperature, concentration, contact time as well as dynamics of the process. The Langmuir, Freundlich and Dubinin-Raduskevich isotherm models for the adsorption processes were tested but Freundlich isotherm provided the best description for adsorption of the dye solution onto the iron filings, suggesting a physisorption controlled adsorption. The adsorption process was highly $\mathrm{pH}$-dependent and the result indicates that the optimum $\mathrm{pH}$ for adsorption of Naphthol AS onto the adsorbent occurred at 4.0 having a maximum removal efficiency of $88 \%$ respectively. Pseudo first-order and second-order as well as the intra-particle diffusivity kinetic models were applied to the experimental data and results showed that the pseudo second-order provided best fit for the experimental data. Kinetic studies also showed that the adsorption transport mechanism was particle-diffusion controlled.
\end{abstract}

Key-Words: Dye, Adsorption, Equilibrium, Isotherm and kinetics

\section{INTRODUCTION}

The control of water pollution has become of increasing importance in recent years as a result of various anthropogenic activities. The discharge of dyes into the environment constitutes a minute proportion of water pollution, but the brilliance nature of dyes makes them visible when present even in very small amounts. Dyes usually possess a synthetic origin and complex aromatic molecular structures, which enhances their stability and renders them non-biodegradable and hazardous [1]. Lately, there are more than 10,000 available commercially synthesized dyes [2]. Although dyes are widely used in textiles, paper, rubber, plastics, cosmetics, pharmaceutical and food industries, the extensive use of dyes often results in pollution problems in the form of colored wastewater discharged into environmental water bodies. It not only affects aesthetic merit but also reduces light penetration and in addition, some dyes are either toxic or mutagenic and carcinogenic [3]. Thus the use of dye contaminated water without any prior treatment may cause adverse effects on human, animal and plant health such as gene mutation, various allergies, contact dermatitis as well as being cancerous. Therefore it is necessary to treat industrial effluents before discharging them into the environment [4]. Naphthol AS is an organic compound with the formula $\mathrm{C}_{10} \mathrm{H}_{6}(\mathrm{OH}) \mathrm{C}(\mathrm{O}) \mathrm{NHC}_{6} \mathrm{H}_{5}$ (Fig 1). It is the anilide of 3-hydroxy-2-carboxynaphthalene. They are insoluble azo dyes applied to cellulosic fibres as a coupling agent by impregnation in an alkaline solution and subsequent coupling with a color salt. In the presence of strong alkali they are converted to the corresponding naphtholate ions and are water soluble. Naphthol AS consists of an arylamide group which has been judged to be carcinogenic. Naphthol AS and its water soluble form can easily be absorbed by the body either through skin contact, ingestion or inhalation [5]. Dyes containing arylamide groups may also be toxic to aquatic organisms and cause long-term adverse effects in the aquatic environment hence their removal is very much of essence.<smiles>O=C(Nc1ccccc1)c1cc2ccccc2cc1O</smiles>

Fig 1: Structure of Naphhtol AS

There are several conventional ways of treating dye contaminated wastewater; some of these technologies are ozonation, ion-exchange and ultrafiltration. Although, they have recorded significant success rates, but their major setback lies in their lack of sustainability due to high cost and sometimes an accompanying discharge of toxic chemicals into the environment. Adsorption using various materials like silica, plant and animal wastes and carbon as adsorbents has also proven to be a very sustainable and cost effective 
alternative in wastewater treatment, with little or no waste generation. Iron filings were used in this study as an environmentally friendly, economical, highly efficient and available adsorbent, to investigate its adsorption capacity in the removal of Naphthol AS from aqueous solutions.

\section{Materials and methods}

Chemicals used in this study were analytical grade. The iron filings and Naphthol AS were commercially purchased from LOBA CHEMIE Colado, Mumbia, India. The iron filings were further characterized using Fourier transform infra-red (FTIR), X-ray diffraction (XRD) and Scanning Electron microscopy (SEM).

\section{Preparation of dye solution}

A $500 \mathrm{mg} / \mathrm{L}$ of the dye solution was prepared by dissolving $0.125 \mathrm{~g}$ of Naphthol AS in $10 \mathrm{ml}$ of $0.1 \mathrm{M}$ sodium hydroxide (due to the dye's insolubility in water) with $5 \mathrm{ml}$ of methylated spirit (acting as stabilizer). The solution was placed in $250 \mathrm{ml}$ volumetric flask and made up to the mark with distilled water. From this stock solution, various concentration ranges of 100 $\mathrm{mg} / \mathrm{L}$ to $10 \mathrm{mg} / \mathrm{L}$ were prepared. The maximum absorption wavelength of the dye was determined by scanning samples with deferent concentrations using UV-Vis Spectrophotometer (UV-1800PC) at a wavelength of $800-380 \mathrm{~nm}$, and the maximum absorption wavelength for Naphthol AS was found at $400 \mathrm{~nm}$.

\section{Characterization of the adsorbent}

The iron filings were characterized with Fourier transform infra-red (FTIR), X-ray diffraction (XRD) and Scanning Electron microscopy (SEM). XRD patterns were recorded using a high-resolution Bruker D8 Advance Diffractometer of $\mathrm{Cu} \mathrm{K \alpha}(\lambda=1.54050 \AA)$ radiation. The samples $(1 \mathrm{~g})$ were scanned from $15^{\circ}$ to $90^{\circ} 2$ Theta range with a step size of $0.02^{\circ}$ and a step rate of $0.454^{\circ} \mathrm{s}^{-1}$. Infrared spectra were obtained by using a Fourier transform infrared spectrometer (FTIR) (Perkin-Elmer Spectrum RX1). The analysis was performed to ascertain the surface functional groups. The powder samples $(99 \mathrm{mg}$ ) were mixed well with 1 $\mathrm{mg}$ of potassium bromide ( $\mathrm{KBr}$ ) and pressed into pellets under vacuum, until they appeared clear and not translucent. The pellets were then carefully removed from the disc, placed in the FTIR sample holder and analyzed by the transmission mode with a resolution of $4 \mathrm{~cm}^{-1}$. The spectra of the different samples were recorded in the wavenumber range of 4000 to $400 \mathrm{~cm}^{-1}$. The morphology of the iron filings was characterized with a Scanning Electron Microscope (SEM) (JSM5910, UK).

\section{Batch adsorption studies}

Batch adsorption experiments were generally carried out by agitating the $150 \mathrm{~mL}$ volumetric flasks containing $1.0 \mathrm{~g}$ adsorbent and $50.0 \mathrm{~mL}$ solution of dye ions on a rotary shaker at 200 $\mathrm{rpm}$ for $60 \mathrm{~min}$. The effect of $\mathrm{pH}$ was conducted at metal ion concentrations of $50 \mathrm{mg} / \mathrm{L}$ in the $\mathrm{pH}$ range of $2-12$ at $30{ }^{\circ} \mathrm{C}$. The $\mathrm{pH}$ values of the solutions were adjusted using $0.01 \mathrm{M}$ hydrochloric acid or/and sodium hydroxide aqueous solutions. To investigate the influence of adsorbent dosage, the batch adsorption was operated at adsorbent masses varying from 1 to 8 g. To explore the isotherms, the batch adsorption was operated at metal concentrations varying from 10.0 to $100 \mathrm{mg} / \mathrm{L}$ and different temperatures ranging from 30 to $80{ }^{\circ} \mathrm{C}$. For the study of the effect of contact time, $1.0 \mathrm{~g}$ of adsorbents were dispersed in $50.0 \mathrm{~mL}$ of dye solution $(50.0 \mathrm{mg} / \mathrm{L})$ at $\mathrm{pH} 4$, and kept continuously stirring for 20 to $120 \mathrm{~min}$. At designed contact time, $2.0 \mathrm{~mL}$ of the suspension was withdrawn, and the dye concentration in the supernatants was analyzed by the uvspectrophotometer at $400 \mathrm{~nm}$ after the adsorbent was removed using Whatman filter paper. Removal efficiencies (\% R) were calculated as follows: $\% \mathrm{R}=\frac{\mathrm{Co}-\mathrm{Ce}}{\mathrm{Co}} \boldsymbol{X} 100$

where $\mathrm{Co}$ and $\mathrm{Ce}(\mathrm{mg} / \mathrm{L})$ are the initial and the equilibrium concentrations of the dye, respectively.

\section{Results and discussion}

XRD patterns of the iron filings: The adsorbent's crystalline phase was identified by X-ray diffraction (XRD) (Fig. 2.). The XRD pattern showed three characteristic peaks (110), (200), and (211) at $2 \theta$ angle values of $44.662^{\circ}$, $65.006^{\circ}$ and $82.311^{\circ}$ which are in line with the main phases and planes of pure iron diffraction peaks when compared with the JCP2 06-0696 Iron $\mathrm{Fe}$ file. From these results, it can be seen that the preferred crystal orientation of the iron filings is in (110) direction, this is because of the strong diffraction peak observed at this plane.

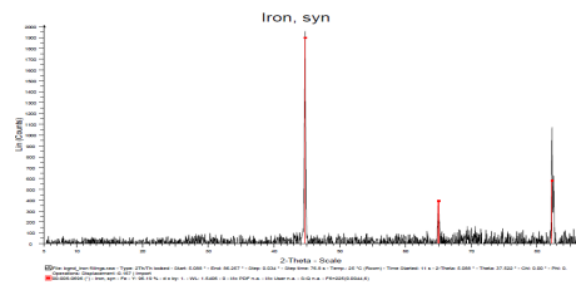

Fig.2 XRD pattern of iron filings

SEM-Result: SEM result showing the morphology of the iron filings is shown in Fig 3. 
The iron filings appeared spherical and partly agglomerated.

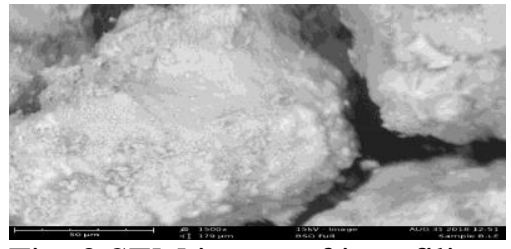

Fig. 3 SEM image of iron filings

FT-IR Result: The FTIR spectrum of iron filings was characterized by three strong bands around $3479.82,1643.88,1414.32$ and 750.43 $\mathrm{cm}^{-1}$ (Fig. 5). These vibrational bands could be assigned as $750.43 \mathrm{~cm}^{-1}(\mathrm{Fe}), 1414.32,1643.88$ and $3479.82 \mathrm{~cm}^{-1} \quad\left(\mathrm{H}_{2} \mathrm{O}\right.$ bending vibration $)$.

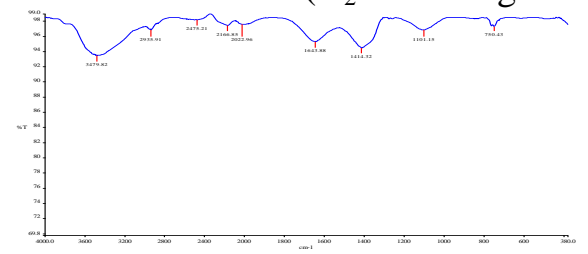

Fig. 5 FTIR spectra of iron filings

\section{Effect of pH on the adsorption of Naphthol AS onto iron filings}

The $\mathrm{pH}$ of an aqueous solution is an important factor affecting both the availability of dyes in solution and the number of binding sites on the adsorbent [6]. The percentage dye removal increased as $\mathrm{pH}$ increased up to $\mathrm{pH} 6$ with maximum removal efficiency of $93 \%$ and then decrease remarkably with $\mathrm{pH}$ increasing from 6.0 to 12.0, which is exhibited in Fig. 6. This observation can be attributed to the structure of the dye molecule, sodium hydroxide solvent and the zero point charge $\left(\mathrm{pH}_{\mathrm{ZPC}}\right)$ of the iron filing. The $\mathrm{pH}_{\mathrm{ZPC}}$ for iron filing is approximately 4.0. At $\mathrm{pH}$ lower than 4.0, the surface of the iron filings acquire a positive charge and the positive charge of the dye is altered by the sodium hydroxide solvent, making it slightly alkaline, resulting to a slight electrostatic attraction between the dye molecule and the iron filings which causes increase in dye adsorption. Above this $\mathrm{pH}$, the surface charge of the iron filings becomes negative, causing a lesser dye uptake since dye molecules tend towards neutral $\mathrm{pH}$.

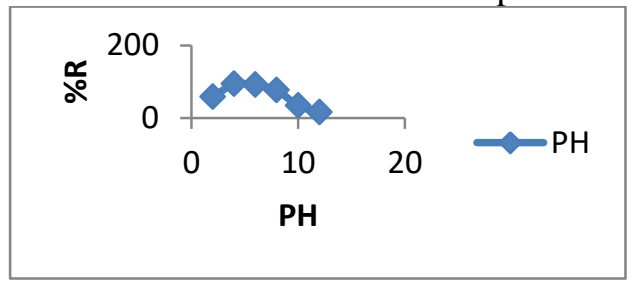

Fig. 6: Percentage removal of Naphthol AS using iron filing adsorbent at different $\mathrm{pH}$ values.

\section{Effect of adsorbent dosage}

The result as shown in Fig. 7 indicates that \% removal of the dye with iron filings increased with increase in the adsorbent dosage, and according to Zhang et al.2008 [7], increase in adsorbent dosage seems to promote more active sites, which facilitates the adsorption of dyes. Increasing the iron filings dose from 1 to $8 \mathrm{~g}$ enhanced the \% removal from 87 to $95.70 \%$, hence dosage increase of iron filings has a marked positive effect on dye uptake.

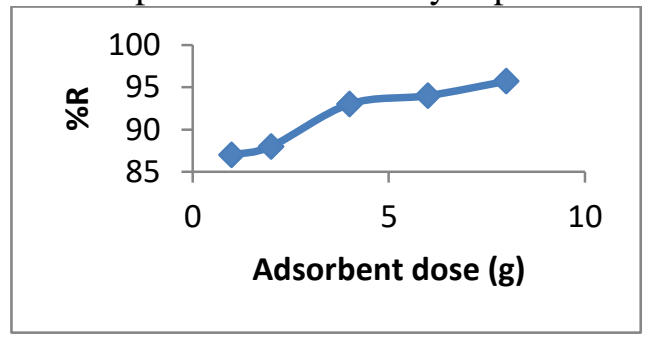

Fig. 7: \% removal of Naphthol AS using iron filings adsorbed at different adsorbent dosage

\section{Effect of contact time}

Equilibrium time is one of the important parameters for an economical wastewater treatment system. It was observed from the result that increased contact time led to a corresponding increase in removal efficiency. Maximum dye adsorption occurred at a contact time of 60 minutes as shown in Fig. 8, having a percentage removal of $94.8 \%$, after which there was a leveling effect, indicating attainment of equilibrium for the adsorption process.

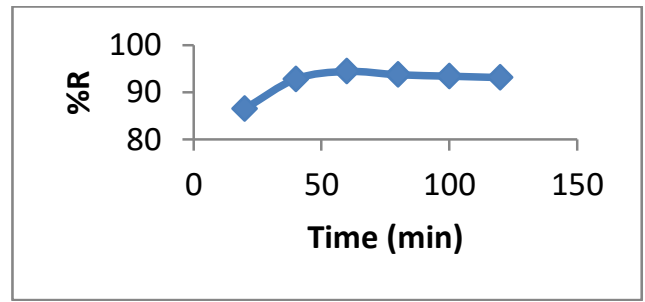

Fig. 8: \% removal of Naphthol AS using iron filings adsorbed at different contact time

\section{Effect of initial dye concentration}

Figure 9 shows the \% removal of Naphthol AS by the iron filings, at various dye concentrations. Results show that \% removal increased proportionally with the dye concentration. At lower concentration, fractional adsorption (the ratio between the numbers of dye molecules to the number of available sites) is low and adsorption is independent on initial dye concentration. Conversely, as the concentration increased, fractional adsorption ratio also increased, thus giving higher adsorption. 
Concentration provides an important initial driving force to overcome all the mass transfer resistance between the aqueous and the solid surfaces; hence, a higher initial dye concentration enhances the sorption process [8]. The adsorption efficiency of the iron filings with respect to the dye solution, increased from $10 \%$ to $80.8 \%$ with equilibrium attained at about $100 \mathrm{mg} / \mathrm{L}$.

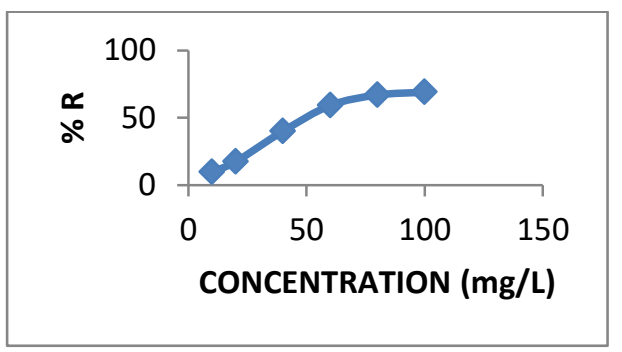

Fig. 9: Percentage removal of Naphthol AS using iron filings adsorbed at different initial concentrations

\section{Adsorption isotherms}

Adsorption isotherm is established when the concentration of an adsorbate (dye) in a bulk solution $\left(\mathrm{C}_{\mathrm{e}}\right)$ is in dynamic balance with that at the interface. Langmuir, Freundlich, Temkin, Redlich-Peterson and Dubinin - Radushkevich isotherm models were used to evaluate the isotherm models in this study. However, Freundlich isotherm best described the experimental data as provided below.

\section{Equilibrium Freundlich Isotherm}

The Freundlich isotherm is generally applicable to adsorption occurring on a heterogeneous surface. The linearized form of Freundlich adsorption isotherm is represented as: $\ln q_{e}=\ln k_{F}+\frac{1}{n} \ln C_{e}$

$\mathrm{K}_{\mathrm{F}}$ and $\mathrm{n}$ are Freundlich constants describing both the intensity and capacity of the adsorption process, respectively. Figure 11 is a linear plot of $\ln \mathrm{q}_{\mathrm{e}} \mathrm{vs} \ln \mathrm{C}_{\mathrm{e}}$, according to Freundlich isotherm equation. $K_{F}$ and $1 / n$ were calculated from the intercept and slope of the linear Freundlich isotherm plot. Assessment of the $\mathrm{R}^{2}$ value shows that the adsorption process has a good fit to the Freundlich model. The correlation coefficient $\left(\mathrm{R}^{2}\right)$ value indicates that Freundlich isotherm clearly described the adsorption process. Treybal [9] had reported that ' $n$ ' values between 1 and 10 represent favorable adsorption conditions. The value of $\mathrm{n}$ was 0.1784 for this study indicating beneficial adsorption for the system. According to Anusiem et al. [10], the fit of experimental adsorption data to Freundlich model indicates that the forces of adsorption by the adsorbents are governed by physisorption. The Freundlich constants and the $\mathrm{R}^{2}$ value are presented in Table 1.

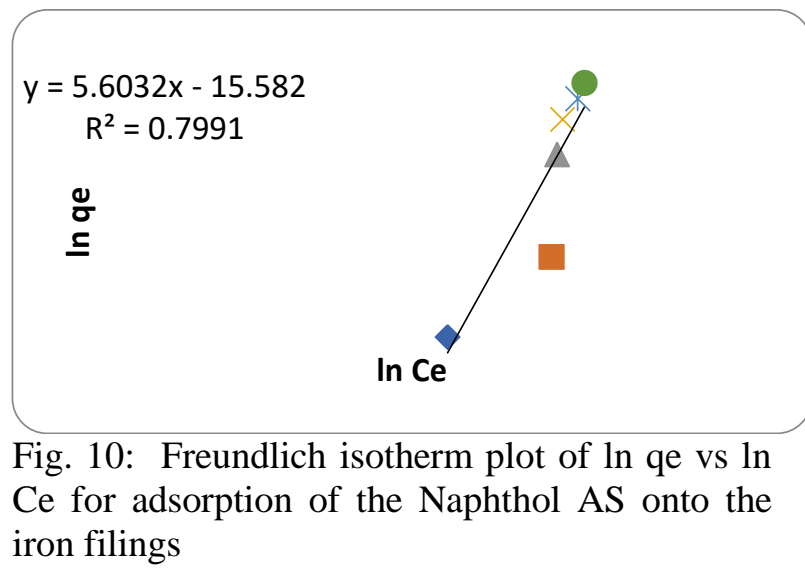

Table 1: Freundlich parameter for the adsorption of Naphthol AS onto iron filing

\begin{tabular}{ccccc}
\hline Adsorbent & Slope & $\ln \mathrm{K}_{\mathrm{F}}$ & $\mathrm{N}$ & $\mathrm{R}^{2}$ \\
\hline Iron filings & 5.6032 & -15.582 & 0.1784 & 0.7991 \\
& & & & \\
\hline
\end{tabular}




\section{Adsorption kinetics}

Adsorption kinetics is an efficient method of evaluating the rate and mechanism of dye solutions adsorption onto the adsorbents. In our present study, three different adsorption kinetic models viz; pseudo first-order, pseudo secondorder and the intra-particle diffusion models [11, $12,13]$ were used to analyze the experimental data. The conformity between the experimental data and the model-predicted values is given by the correlation coefficients $\left(\mathrm{R}^{2}\right.$ values close or equal to 1 ). A relatively high $\mathrm{R}^{2}$ value shows that the model successfully describes the kinetics of the adsorption process. The various kinetic models are described in the subsections below:

\section{The Pseudo First-Order Model}

The integrated pseudo first-order equation is generally given as:

$$
\log \left(q_{e}-q_{t}\right)=\log \left(q_{e}\right)-\frac{k_{1}}{2.303} t
$$

Where $\mathrm{q}_{\mathrm{e}}$ and $\mathrm{q}_{\mathrm{t}}$ are the adsorption capacities $\left(\mathrm{mg} \mathrm{g}^{-1}\right)$ at equilibrium and at a time $\mathrm{t}$, respectively, $\mathrm{k}_{1}$ is the rate constant of pseudo first-order adsorption $\left(\mathrm{min}^{-1}\right)$. The plots of $\log$ $\left(\mathrm{q}_{\mathrm{e}}-\mathrm{q}_{\mathrm{t}}\right)$ vs. $\mathrm{t}$ gave linear straight lines from which $\mathrm{k}_{1}$ and $\mathrm{q}_{\mathrm{e}}$ were determined from the slope and intercept of the linear plots and are presented in Table 2. Figure 12 shows the linear plots for the pseudo first-order model for the adsorption process.

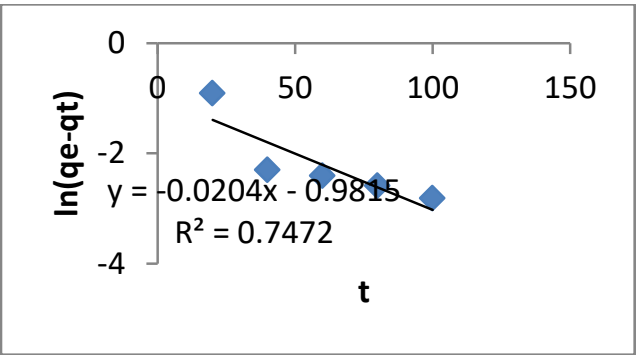

Fig. 11: Pseudo-first order plot of $\ln \left(\mathrm{q}_{\mathrm{e}}-\mathrm{q}_{\mathrm{t}}\right)$ vs $\mathrm{t}$ for adsorption of the dye onto iron filings

\section{Pseudo Second-Order Kinetic Model}

The integrated Pseudo second-order model is usually given as:

$$
\frac{t}{q_{t}}=\frac{1}{k_{2} q_{e}^{2}}+\frac{t}{q_{e}}
$$

Where $\mathrm{h}_{\mathrm{o}}=\mathrm{k}_{2} \mathrm{q}_{\mathrm{e}}^{2}$ is described as the initial adsorption rate as $\mathrm{t}$ approaches zero. The pseudo second-order model was applied in this analysis and a plot of $\mathrm{t} / \mathrm{q}_{\mathrm{t}}$ vs $\mathrm{t}$ yielded a linear plot, which allowed the evaluation of $\mathrm{q}_{\mathrm{e}}, \mathrm{k}_{2}$ and $\mathrm{h}_{\mathrm{o}}$. According to Ho et al. [11], if the plots are linear, then the adsorption process may be described as chemisorption. As shown in Table 2 and Figures 13, the adsorption data of the adsorbents fitted the pseudo second-order model perfectly depicted by the high correlation coefficients $\left(\mathrm{R}^{2}=0.999\right)$. This suggests that the rate-limiting step of the dye solution adsorption by the adsorbents in our study may be controlled by chemisorption.

The rate constant, $k_{2}$, the equilibrium adsorption capacity, $q_{\mathrm{e}}$ and the initial sorption rate, $h_{o}$, of the adsorption of dye solution are presented in Table 2. These parameters were calculated from the intercept and slope of the linear plot of $t / \mathrm{q}_{\mathrm{t}}$ versus $t$. The equilibrium adsorption capacities $\mathrm{q}_{\mathrm{e}}$ calculated from the pseudo second-order kinetic model agree very closely with the experimental value.

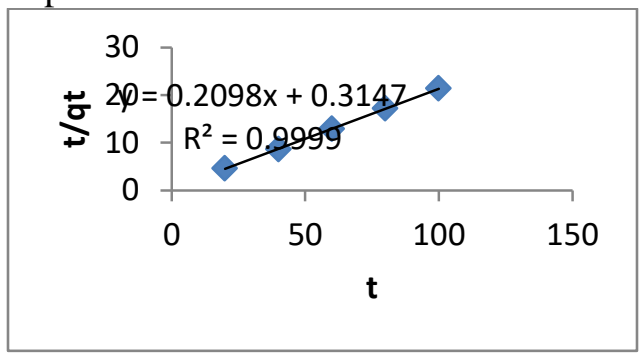

Fig. 12: Pseudo-second order plot of t/qt vs $t$ for adsorption of the dye solution onto iron filings

Table 4 shows the kinetic rate constants for pseudo-second order reaction at $30{ }^{\circ} \mathrm{C}$

A comparison of the two kinetic models using the $R^{2}$ values to determine the best fit, pseudo second-order provided a better description for the kinetics of the dye adsorption process, with an $R^{2}$ value of 0.999 .

\section{Intra-Particle Diffusion}

Intra-particle diffusion model was applied to the experimental data to describe the mechanism at different adsorption times in order to determine the actual rate limiting step controlling the adsorption of Naphthol AS onto iron filings. According to Weber and Morris [13], an adsorption process is influenced by intra-particle diffusion and a plot of the adsorption capacity (qt) with the square root of time should have a linear variation. The intra-particle diffusion model is expressed as follows: $q_{t}=X_{i}+K^{i} t^{1 / 2}$ 
Where qt is the fraction of dye uptake $(\mathrm{mg} / \mathrm{g})$ at time $\mathrm{t}$, $\mathrm{ki}$ is the intraparticle diffusion rate constant $\left(\mathrm{mg} /\left(\mathrm{g} \min ^{1 / 2}\right)\right.$ and $\mathrm{xi}$ as intercept $(\mathrm{mg} / \mathrm{g})$. A plot of $\mathrm{qt}$, versus $\mathrm{t}^{1 / 2}$ (Fig. 13) will give ki as slope and $x_{i}$ as intercept and results are presented in Table 2. The xi represents the effect of boundary layer thickness. From Fig. 14, the plots are non linear in nature but we could infer that data points can be better represented by double linear with difference in slope $\left(\mathrm{k}_{1}\right)$ and intercept $\mathrm{x}_{\mathrm{i}}$. In this first straight line, the sudden increase in slope signifies that the dye molecules are transported to the external surface of iron filings through film diffusion and its rate is very fast. After this, dye molecules passes into the iron filings by intra-particles through pore, which is represented by the second straight line. Both lines do not pass through the origin implying that both film and intra-particle diffusions are simultaneously occurring during the adsorption of dye onto the iron filings [14].

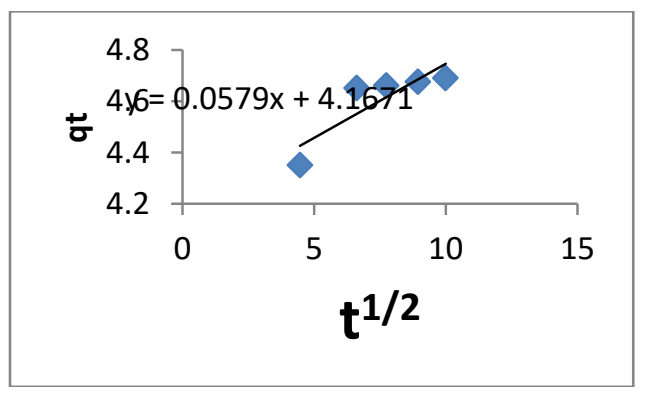

Figure 13 Weber and Morris Intraparticle diffusion plot for adsorption of Naphthol AS onto iron filings
Table 2 Kinetic rate constants for pseudo firstorder and pseudo second order reactions and intra-particle diffusion model at $30^{\circ} \mathrm{C}$

\begin{tabular}{|c|c|c|}
\hline \multirow[t]{2}{*}{ Pseudo first } & Constants & Values \\
\hline & $\begin{array}{l}\mathrm{q}_{\mathrm{e} \mathrm{calc}}\left(\mathrm{mg} \mathrm{g}^{-1}\right) \\
\mathrm{q}_{\mathrm{e} \exp }\left(\mathrm{mg} \mathrm{g}^{-1}\right) \\
\mathrm{k}_{1}\left(\min ^{-1}\right) \\
\mathrm{R}^{2}\end{array}$ & $\begin{array}{l}0.375 \\
4.040 \\
2.04 \times 10^{-2} \\
0.281\end{array}$ \\
\hline $\begin{array}{l}\text { Pseudo-second } \\
\text { order }\end{array}$ & $\begin{array}{l}\mathrm{q}_{\mathrm{e} \text { calc }}(\mathrm{mg} / \mathrm{g}) \\
\mathrm{q}_{\mathrm{e} e x p}(\mathrm{mg} / \mathrm{g}) \\
\mathrm{k}_{2}\left(\mathrm{~g} \cdot \mathrm{mg}^{-}\right. \\
\left.{ }^{1} \mathrm{~min}^{-1}\right) \\
\mathrm{h}_{\mathrm{o}}\left(\mathrm{mg}^{-1} \mathrm{~g}^{-1} \mathrm{~min}^{-}\right. \\
\left.{ }^{1}\right) \\
\mathrm{R}^{2}\end{array}$ & $\begin{array}{l}4.803 \\
4.040 \\
0.5334 \\
0.3903 \\
0.999\end{array}$ \\
\hline $\begin{array}{l}\text { Webber- } \\
\text { Morris } \\
\text { intraparticle } \\
\text { diffusion } \\
\text { model }\end{array}$ & $\begin{array}{l}\mathrm{X}_{\mathrm{i}}(\mathrm{mg} / \mathrm{g}) \\
\mathrm{K}^{!}(\mathrm{mg} / \mathrm{g}- \\
\left.\min ^{0.5}\right) \\
\mathrm{R}^{2}\end{array}$ & $\begin{array}{l}4.3462 \\
4.46 \times 10^{-2} \\
0.7947\end{array}$ \\
\hline
\end{tabular}

\section{Conclusion}

This study investigates the potential of iron filings in the adsorption of the dye (Naphthol AS) solution. The effects of $\mathrm{pH}$, contact time, adsorbent dosage, temperature, concentration and dynamics of the process were examined. The data obtained from the adsorption isotherms are well fitted with Freundlich model which suggests the multilayer coverage of the dyes on surfaces of iron filings. Removal of Naphthol $\mathrm{AS}$ is $\mathrm{pH}$ dependent and the maximum removal was attained at $\mathrm{pH}$ 4.0. Kinetic studies showed that adsorption of Naphthol AS followed pseudo second-order kinetic model. Environmental effects of the iron filings to ascertain its safety in the environment is also strongly suggested. It can be concluded from this study, that the adsorbent could be good and economical substrate for the removal of Naphthol AS from aqueous solutions and may possibly be useful for treating industrial wastewaters.

\section{Reference}

[1] S. Seshadri, P. L.Bishop, and A. M. Agha. (1994). Anaerobic/aerobic treatment of selected azo dyes in 
wastewater, Waste Manage, 15, 127137.

[2] P. Nigam, G. Armour, I.M. Banat, D. Singh and R. Marchant. (2000). Physical removal of textile dyes from effluents and solid-state .Biores Technol., 72, 219-226.

[3] D. Xu, C. Gu, X. Chen (2013). Adsorption and removal of acid red $3 \mathrm{R}$ from aqueous solution using flocculent humic acid isolated from lignite Procedia Environmental Sciences 18: $127-134$

[4] S.E. Agarry and O.B.Solomon. (2008). Kinetics of batch microbial degradation of phenols by indigenous Pseudomonas fluorescence. Int. J. Environ. Sci. Tech., 5(2): 223- 232

[5] K. Hunger. and W. Herbst. (2012). "Pigments, Organic". Ullmann's Encyclopedia of Industrial Chemistry. Weinheim: Wiley-VCH. P.201

[6] A.A. Farghali, M. Bahgat, A. Enaiet Allah and M.H. Khedr. (2013). Adsorption of $\mathrm{Pb}(\mathrm{II})$ ions from Aqueous Solutions Using Copper Oxide Nanostructures. Journal of Basic and Applied Sciences, 2:61-71

[7] X. Zhang and R.B. Bai. (2003). Mechanisms and Kinetics of Humic Acid Adsorption onto Chitosan-coated Granules, J. Colloid Interf. Sci., 264: 3038.

[8] S. Patil, S. Renukdas and N. Patel. (2011). Removal of methylene blue, a basic dye from aqueous solutions by adsorption using teak tree (Tectona grandis) bark powder. Int J Environ Sci 1:711- 726

[9] A.C.I. Anusiem, F.K. Onwu, and S.P. Ogah. (2010). Adsorption Isotherms Studies of Ni (1l), Cd (1l) and $\mathrm{Pb}$ (11) ions from Aqueous Solutions by African White Star Apple (Chrysophyllum albidium) Shell. Int. Journ. Chem. 20 (4): 265-274 .

[10] R.E. Treybal. (1980). Mass transfer operations, McGraw Hill, $3^{\text {rd }}$ edition New York: 447-522

[11] Y.S. Ho, G. McKay, D.A.J. Wase and C.F. Foster. (2000). Study of the sorption of divalent metal ions onto peat. Adsorp. Sci. Technol. 18: 639-650.

[12] S.K. Srivastava, R. Tyagi and N. Pant. (1989). Adsorption of heavy metal ions oncarbonaceous material developed from the waste slurry generated in localfertilizer plants. Water Res. 23: 1161-1165.

[13] W.J. Webber and J.C. Morris (1963). Kinetics of Adsorption On Carbon From Solution, J. Sanit. Eng. Dir. Am. Soc. Cir. Eng., 89: $31-60$.

[14] A.I. Zouboulis, K.A. Matis, M. Loukidou and F. Sebesta. (2013). MetalBiosorption by PAN-Immobilized Fungal Biomass in Simulated Wastewaters, Coll. Surf. A 212: 185-196 